\title{
Regulation of Arabidopsis root development by small signaling peptides
}

\section{Christina Delay, Nijat Imin and Michael A. Djordjevic*}

Division of Plant Sciences, Research School of Biology, College of Medicine, Biology and Environment, The Australian National University, Canberra, ACT, Australia

\section{Edited by:}

Wolfgang Schmidt, Academia Sinica, Taiwan

\section{Reviewed by:}

Ive De Smet, Vlaams Instituut voor Biotechnologie, Belgium

Reidunn Birgitta Aalen, University of Oslo, Norway

\section{${ }^{*}$ Correspondence:}

Michael A. Djordjevic, Division of Plant Sciences, Research School of Biology, College of Medicine, Biology and Environment, The Australian National University, Linnaeus Bld. 134, Linnaeus Way, Canberra, ACT 0200, Australia

e-mail: michael.djordjevic@anu.edu.au
Plant root systems arise de novo from a single embryonic root. Complex and highly coordinated developmental networks are required to ensure the formation of lateral organs maximizes plant fitness. The Arabidopsis root is well-suited to dissection of regulatory and developmental networks due to its highly ordered, predictable structure. A myriad of regulatory signaling networks control the development of plant roots, from the classical hormones such as auxin and cytokinin to short-range positional signaling molecules that relay information between neighboring cells. Small signaling peptides are a growing class of regulatory molecules involved in many aspects of root development including meristem maintenance, the gravitropic response, lateral root development, and vascular formation. Here, recent findings on the roles of regulatory peptides in these aspects of root development are discussed.

Keywords: small signaling peptides, small post-translationally modified peptides, regulatory peptides, root development, CLE, RGF/CLEL/GLV, IDA, CEP

\section{INTRODUCTION}

The entire plant root system is formed post-embryonically from a single primary root. Growth and development of this system requires coordinated regulation of hardwired developmental programs together with input from environmental signals (Casimiro et al., 2003; Malamy, 2005). While the classical phytohormones are key players in many aspects of root development, cell-to-cell communication is a vital component of most developmental processes. Regulatory peptides are one class of small signaling molecules that mediate intercellular communication. Roles for small signaling peptides in shoot development have been elucidated and are relatively well-characterized (Fukuda and Higashiyama, 2011). Recently, there has been a leap in our understanding of the roles of regulatory peptides in root development.

Small signaling peptides arise from genes that typically encode an N-terminal signal peptide region, one or more conserved peptide domains and variable regions that flank one or both sides of the discrete peptide domains. There are two structural classes of signaling peptides: small (5-20 amino acids) posttranslationally modified peptides, which are the focus of this review; and larger cysteine-rich peptides (approximately 50 amino acids) that undergo disulfide bond formation as part of the maturation process. Common post-translational modifications to the smaller peptides class include hydroxylation, sulfation, and arabinosylation. These modifications may increase peptide stability, assist with receptor interactions and provide a further degree of regulation. The precursor proteins undergo processing to form the mature peptide product. While the maturation process is poorly understood, it was recently shown that four residues upstream of the peptide domain are required for CLE (CLAVATA3/ESRrelated) peptide endoproteolytic processing ( $\mathrm{Ni}$ et al., 2011). Most peptides are thought to act as extracellular signaling molecules that are ligands for membrane bound receptors although few ligand/receptor interactions have been validated (Matsubayashi et al., 2002; Hirakawa et al., 2008; Ogawa et al., 2008).

Several families of regulatory peptides, defined by homology of the peptide domain, have been implicated in various developmental processes in the roots. The CLE peptide family has a conserved 12-14 amino acid CLE motif at or near the C-terminus (Cock and McCormick, 2001). The RGF (ROOT GROWTH FACTOR) family of peptides, also known as GLV (GOLVEN) and CLEL (CLE-Like), has a conserved 14 amino acid peptide domain containing the tyrosine sulfation motif Asp-Tyr (Matsuzaki et al., 2010; Meng et al., 2012b; Whitford et al., 2012). The IDA (INFLORESCENCE DEFICIENT IN ABCISSION) peptide family has conserved, functionally active 20 amino acid motif (EPIP; Butenko et al., 2003; Stenvik et al., 2008). The CEP (C-TERMINALLY ENCODED PEPTIDE) family has a conserved 15 amino acid peptide domain with two proline residues that may be hydroxylated (Ohyama et al., 2008).

Recent work implicates regulatory peptides in many aspects of root growth and development, including meristem maintenance, gravitopism, lateral root (LR) development, and protoxylem differentiation (Figures 1A-G). This review outlines the recently discovered roles of these peptide families in root development.

\section{ROOT MERISTEM MAINTENANCE}

For continual growth and development, roots require a source of new cells that are able to differentiate into various tissue types. The root meristem contains a population of stem cells maintained by the quiescent center (QC). An extraordinary amount of precise regulation is required to ensure that the identity of the QC cells, the surrounding stem cells and their daughters is maintained. Several transcription factors are essential for this. WOX5 (WUSCHEL-related homeobox 5) is expressed in the QC to maintain stem cell identity (Haecker et al., 2004). SCR (SCARECROW) 


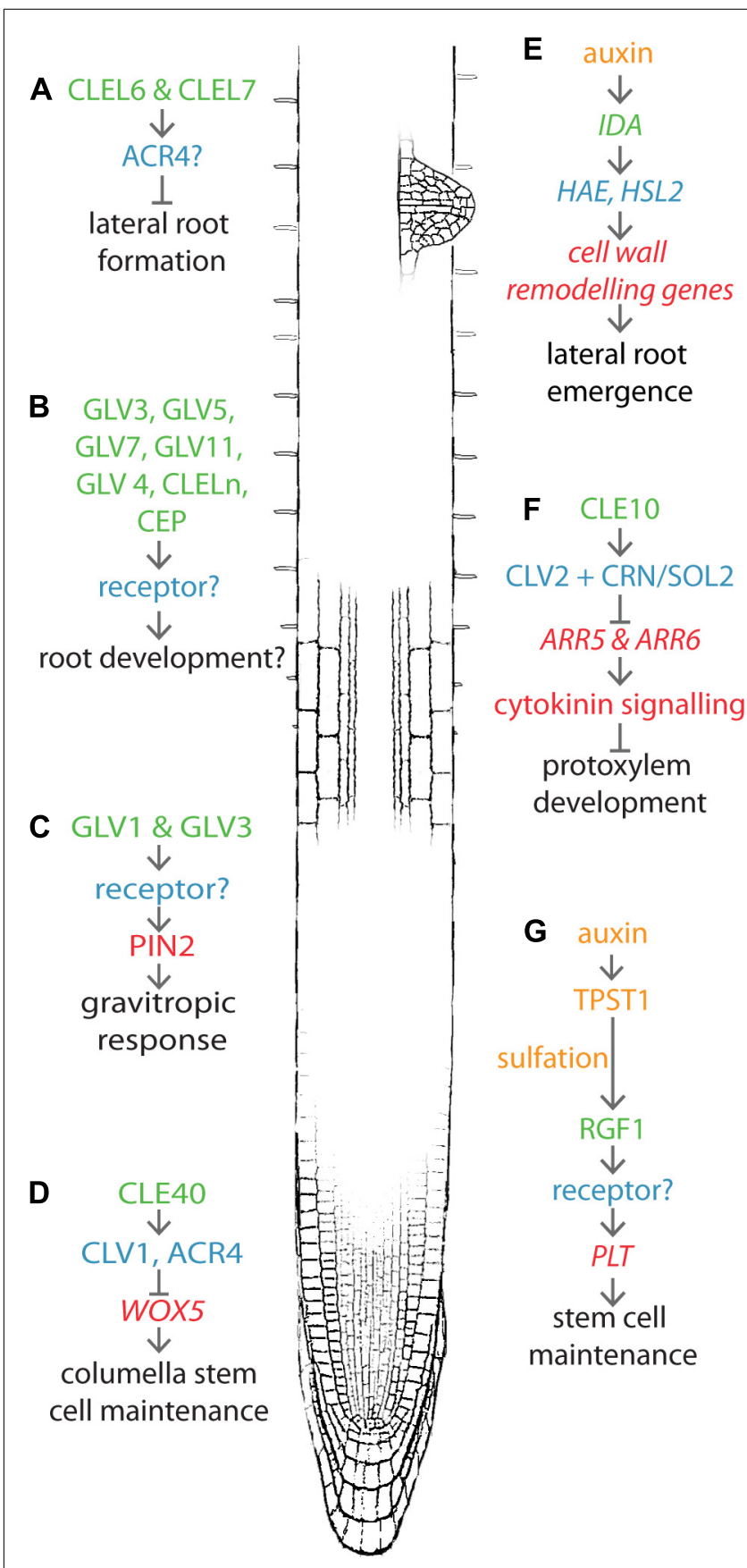

FIGURE 1 | Recent advances in peptide-mediated regulation of root development. CLE, RGF/GLV/CLEL, IDA, and CEP peptides are involved in several aspects of root development including lateral root formation (A), (B), (D), (E), protoxylem development (F), stem cell maintenance (G), and gravitropic response (C). Known pathways discussed in this review are shown near their approximate location in the root. Peptides are indicated in green text, receptors in blue. Upstream processes are yellow and downstream processes are red. Developmental output is indicated by black text.

and SHR (SHORTROOT) are expressed along the radial axis to provide positional information and also maintain QC identity (Di Laurenzio et al., 1996; Helariutta et al., 2000; Sabatini et al., 2003). PLT1 (PLETHORA1) and PLT2 (PLETHORA2) are auxin responsive genes that form a gradient distribution to maintain stem cell identity when expressed at high levels and promote differentiation when present at low levels (Aida et al., 2004; Galinha et al., 2007). An auxin maximum is also required in the stem cell niche (Sabatini et al., 1999; Friml et al., 2003).

A recent report implicated the CLE40 peptide in maintaining QC and columella stem cell identity (Figure 1D; Stahl et al., 2009). CLE40 is expressed in the stele and in differentiating columella cells. cle40 loss of function mutants had short roots with irregular tips caused by delayed differentiation of columella stem cells. Excessive CLE40 led to columella stem cell differentiation. The expression of WOX5 was perturbed when CLE40 was deregulated, extending beyond the QC in the cle40 mutant and being reduced in the QC and shifted toward the proximal meristem upon CLE40 peptide addition to WT plants. CLE40, together with ACR4 (Arabidopsis CRINKLY 4), a receptor-like kinase, regulated the spatial expression of WOX5 to maintain columella stem cell identity. Additionally, the CLV2 (CLAVATA 2) leucine-rich repeat receptor was found to be necessary for CLE40-dependent root growth suppression, but not for differentiation of the daughters of columella stem cells (Stahl et al., 2009), indicating that the same peptide may interact with more than one receptor to regulate different developmental processes. Indeed, further investigation showed that subcellular localization, environment, and concentration affect the formation of receptor complexes (Stahl et al., 2013). The leucine-rich repeat receptor kinase CLV1 was shown to be involved in the signaling pathway of CLE40 and ACR4 (Figure 1D). ACR4 and CLV1 have similar expression patterns in the root meristem. CLE40 regulates ACR4 expression but not CLV1 expression. Using Förster resonance energy transfer and multiparameter fluorescence image spectroscopy, the transmembrane domains of ACR4 and CLV1 were shown to interact and form homomeric and heteromeric complexes depending on localization (plasma membrane or plasmodesmata). Both the clv1 and acr4 single mutants were impaired in aspects of meristem maintenance and responded differently to CLE40 peptide application. This indicated that the homo- and heteromeric complexes differentially regulate root meristem maintenance.

In another recent report, the sulfated RGF1 peptide was found to regulate meristem maintenance by providing a link between PLT expression and auxin through sulfation by TPST1 (TYROSYLPROTEIN SULFOTRANSFERASE 1; Figure 1G; Matsuzaki et al., 2010; Zhou et al., 2010). The tpst1 mutant displayed pleiotropic effects including decreased meristem size and cell division activity, QC misregulation and starch granule accumulation. This mutant lacked the only copy of tyrosylprotein sulfotransferase found in the Arabidopsis genome (Matsuzaki et al., 2010; Zhou et al., 2010). TPST1 was induced by auxin and helped to maintain auxin distribution by regulating expression of PIN-FORMED (PIN) and auxin biosynthetic genes (Zhou et al., 2010).

The RGF peptide family was found by a bioinformatic search for putatively sulfated peptide-encoding genes (Matsuzaki et al., 2010). Applying synthetic, sulfated RGF1 peptide to tpst1 roots ameliorated the stem cell misregulation phenotype and increased cell division activity, indicating that sulfated RGF1 was required for these processes. Further investigation showed the sulfated peptides PSK (PHYTOSULFOKINE) and PSY1 (PLANT PEPTIDE 
CONTAINING SULFATED TYROSINE 1) were also required for full restoration of cell division activity. Eight of the nine sulfated RGF peptides complemented the tpst 1 mutant in this way, however, non-sulfated peptides were unable to do so. It was found that RGF1 acts by regulating spatial expression and expression levels of PLT transcription factors. This work provided a link between auxin levels, the RGF peptide and PLT expression through TPST1. These studies also exemplified the extra layer of regulation that can be provided by post-translational modification of signaling peptides.

The CEP family has also been shown to affect root meristem development (Ohyama et al., 2008). Several forms of cleaved and modified peptides were confirmed using mass spectrometry on CEP1 overexpression lines. Synthetic 15 amino acid CEP1 peptide application or CEP1 overexpression arrested root growth. Meristematic cell division and expansion was repressed by CEP1, although QC specification was not affected. A more detailed analysis of the CEP family and the mode of action of individual CEPs is required.

\section{VASCULAR DEVELOPMENT}

Once cells leave the meristematic zone of the root, they go through phases of elongation and differentiation into specific tissue types. Procambial and cambial cells differentiate into xylem and phloem, the vascular tissues required for long-distance transport of water and nutrients though the plant. Several regulatory peptides are known to play important roles in vascular development, including the CLE-family member TDIF (TRACHEARY ELEMENT DIFFERENTIATION INHIBITORY FACTOR; Ito et al., 2006). More recently, another member of this family, CLE10, was found to inhibit protoxylem formation through interaction with cytokinin signaling (Figure 1F; Kondo et al., 2011).

A screen for CLE genes up-regulated during vascular development together with synthetic peptide assays implicated CLE10 in early xylem differentiation (Kondo et al., 2011). CLE10 peptide application rapidly down-regulated the transcription of $A R R 5$ and ARR6, two type A Arabidopsis RESPONSE REGULATORs that negatively regulate cytokinin signaling. This indicated that cytokinin signaling was increased by CLE10, leading to decreased protoxylem development, one of the documented roles of cytokinin. The leucine-rich repeat receptor-like protein CLV2 and protein kinase CRN (CORYN)/SOL2 (SUPRESSOR OF LLP2) were both required for CLE10 suppression of ARR5 and ARR6 transcription, indicating they may be the receptor module for the CLE10 peptide.

\section{GRAVITROPIC RESPONSE}

Response to gravity stimulus is an essential component of root development. This process relies on gravity sensing in the root tip together with manipulation of auxin gradients, mediated by the localization of the AUX1/LIKE-AUX1 family of auxin influx carriers and the PIN family of auxin efflux carriers (Vieten et al., 2007). The GLV/RGF peptide family has been implicated in this process (Figure 1C). Using a reverse genetic screen, Whitford et al. (2012) found that GLV1/RGF6, GLV2/RGF9, and GLV3/RGF4 overexpression (or sulfated peptide addition) caused an altered gravitropic response in roots. GLV1/RGF6 and GLV3/RGF4 post-transcriptionally regulated PIN2 within minutes of peptide application, presenting evidence that GLV/RGF signaling controls the trafficking and stability of PIN2. A perturbation in the PIN2 pool would abolish the finely tuned auxin gradient necessary for normal gravitropic response. A loss of function glv3/rgf4 mutant displayed gravitropic defects (Fernandez et al., 2013) implying GLV3/RGF4 is required for correct gravitropic response.

In a separate study, CLEL/RGF genes were found by homology with CLE18, a peptide precursor gene with a CLE motif in the variable region and a CLEL/RGF peptide domain at the C-terminus (Meng et al., 2012a). Unmodified CLEL6/RGF6 and CLEL8/RGF1 peptide application and CLEL6/RGF6 and CLEL7/RGF5 overexpression induced long roots on WT plants as well as an additional "wavy" root phenotype. This wavy root phenotype was reported to be independent of thigmotropism and phototropism. It was also reported to be independent of gravitopism as the phenotype persisted when unmodified CLEL6/RGF6 peptide was applied to eir1-1 and aux1-7 mutants, which are impaired in the gravitropic response. This is in disagreement with the aforementioned study which implicates CLEL6/GLV1/RGF6 in gravitropic response.

Interestingly, the peptide-encoding gene at the center of this debate, CLEL6/GLV1/RGF6, is reportedly not expressed in any part of the root (Whitford et al., 2012; Fernandez et al., 2013). Furthermore, a GLV1/RGF6 knockdown line did not show impaired gravitropic response (Fernandez et al., 2013). This indicates regulation of peptide gene expression is paramount to its in planta function. Excessive peptide treatment by overexpression or peptide application should be interpreted in a biologically relevant context and should be supported by data from loss of function mutants.

\section{LATERAL ROOT DEVELOPMENT}

The formation of LRs allows the plant to exploit water and nutrients in the surrounding soil. LRs arise from a repetitive process which begins in the root meristem region. The earliest described event in LR development is priming or pre-branch site formation. This process requires auxin (De Smet et al., 2007) and the oscillation of over 3,000 genes (Moreno-Risueno et al., 2010). As the cells move into the differentiation zone, a site of relatively low auxin levels, LR founder cells are specified from xylem pole pericycle cells (Dubrovsky et al., 2008, 2011). The founder cells are initiated in an auxin-dependent manner (Dubrovsky et al., 2011) and begin to undergo a series of divisions. Eight stages of LR development have been defined (Malamy and Benfey, 1997), from the first asymmetric division (stage I) through many subsequent rounds of cell division (stages II-VII), to LR emergence (stage VIII). In order for the nascent LR to pass through the cortical, endodermal, and epidermal cell layers before emerging, auxin-dependent degradation and remodeling of cell walls is required (Swarup et al., 2008).

Peptides from the RGF family were reported to regulate LR development in an auxin-independent manner (Figure 1A; Meng et al., 2012a). Overexpression of CLEL6 /RGF6 or CLEL7/RGF5 resulted in a significant reduction in LR number, due to abnormal cell divisions at stage I of LR development. The authors speculated that CLEL6/RGF6 and CLEL7/RGF5 may interact with the 
receptor kinase ACR4, as it too plays an important role in the early stages on LR development. Other RGF genes were found to be specifically expressed during different stages of LR development (Fernandez et al., 2013). Promoter reporter constructs showed that GLV6/RGF8 was active from stage I of LR development, GLV5/RGF2 and GLV10/RGF5 at stage II, GLV7/RGF3 and GLV11/RGF1 at stage IV, GLV3/RGF4 at stage V, and GLV9 and GLV2/RGF9 after emergence. Overexpression of these genes resulted in decreased LR number as well as root waving and enlarged root meristems. These data indicate that RGF peptides may act at different stages of LR development, however, specific mechanisms remain to be elucidated.

The IDA peptide and its receptors, HAE (HAESA) and HSL2 (HAESA-Like 2) were recently shown to play a role in LR emergence (Figure 1E; Kumpf et al., 2013) in addition to their known roles in floral abscission (Butenko et al., 2003; Stenvik et al., 2008). The ida, hae, hsl2 single mutants, and hae hsl2 double mutant showed a significant reduction in the number of LRs (Kumpf et al., 2013). LR primordia in these mutants encountered difficulties in penetrating the cortical, endodermis, and epidermal cell layers and often displayed irregular flattened shapes. IDA was strongly induced by auxin, whereas the two receptors were only transiently induced by auxin, indicating the receptors are used to limit IDA function. Two stages for IDA-mediated cell wall remodeling (CWR) were identified. During early primordia development (stage I and II), auxin from the LR primordium induced IDA expression in the endodermal cells, where HAE and HSL2 were already present. IDA signaling led to the expression of CWR enzymes, which allowed the nascent LR to pass through the endodermal cell layer. At a later stage in primordia development (stage $\mathrm{V})$, auxin was derived from the auxin influx carrier LIKE AUX1-3 (LAX3), expressed in the neighboring cortical and epidermal cells. This induced the degradation of SOLITARY ROOT1 which in turn released the transcription factors AUXIN RESPONSE FACTOR (ARF) 7 and 19. ARF7 was required for the subsequent induction of IDA that triggered the expression of CWR genes through HAE/HSL2 signaling to allow the primordia to emerge from the parent root.

\section{OTHER ROLES OF SMALL SIGNALING PEPTIDES IN ROOT DEVELOPMENT}

A recent report described CLELn (CLE-Like protein in the nucleus), a RGF family gene that lacked the archetypal N-terminal signal sequence (Meng et al., 2012b). A green fluorescent protein (GFP)-fusion assay suggested this peptide localizes to the nucleus and western blots indicated it is specifically processed from the precursor. Overexpression of this gene gave a long root phenotype similar to GLV2/RGF9 overexpression, however, synthetic peptide application elicited the long and wavy phenotype seen when GLV1/RGF6 and GLV11/RGF1 synthetic peptides were assayed. These data raise the possibility that regulatory peptides do not act solely as intercellular signals and may play roles in nuclear signaling or are secreted by non-conventional routes.

Regulatory peptides also play important roles in nodule organogenesis in legumes. Nodules form in response to infection by symbiotic bacteria called rhizobia. This process requires systemic regulation (autoregulation of nodulation; Caetano-Anolles and Gresshoff, 1991), a process that has parallels with shoot meristem regulation in Arabidopsis by CLV3 and CLV1 and their downstream processes (Mayer etal., 1998; Brand etal., 2000; Schoof et al., 2000; Leibfried et al., 2005; Osipova et al., 2012). Two root-specific pathways that involve Nod factors and cytokinin signaling are also required for nodulation. Medicago truncatula CLE12 and CLE13 are up-regulated in nodulating roots (Mortier et al., 2010). Upon overexpression, wild type plants do not form nodules. Suppression of nodulation by MtCLE12 and MtCLE13 is dependent upon SUNN (SUPER NUMERIC NODULES, orthologous to CLAVATA1 in Arabidopsis) and induces type A response regulators, leading to cytokinin signaling (Mortier etal., 2010; Saur etal., 2011). Similar results were found in Glycine max (Reid et al., 2011) and Lotus japonicus (Okamoto et al., 2009), indicating at least two CLE peptides play an essential role in the autoregulation of nodulation. Recently a nodulespecific CLE in L. japonicas (CLE-RS2) was shown to be a root produced arabinosylated peptide (Okamoto et al., 2013). It interacted with HAR1, which shares functional similarity with SUNN, in an arabinose chain and sequence-dependent manner. CLERS2 was found in shoot-collected xylem sap, indicating that the CLE-RS glycopeptide is a long distance, root-to-shoot signal that controls autoregulation. These exciting results add a new dimension to how regulatory peptides control root development.

\section{FUTURE PERSPECTIVES}

Although a number of peptides from the CLE and RGF families have been implicated in different aspects of root development, the specific function and mechanistic action of other family members remains to be elucidated (Figure 1B). In a step toward this, the expression patterns and effects of misregulation of all RGF and CLE peptide family members have been assessed (Jun et al., 2010; Fernandez et al., 2013). Further work is required to elucidate the functions of the CEP family in root development.

While genetic redundancy has hindered elucidation of peptide function by loss of function mutants, a recently reported technology may assist in overcoming this. It was shown that by substituting Gly6 in the CLV3 peptide domain for Ala or Thr, dominant-negative $\operatorname{clv} 3$ phenotypes were obtained (Song et al., 2013). When applied in combination with the unsubstituted CLV3 peptide, it was shown that the antagonistic effect was a result of competition between the two peptides. It was hypothesized that $\mathrm{CLV}_{\text {Thr6 }}$ was able to bind the CLV3 receptor without eliciting a response. This concept was also used to make antagonists for CLE8 and CLE22 peptides. This technology may assist in elucidating the function of specific regulatory peptides.

As highlighted in this review, small signaling peptides play important roles in root development. There are several layers of regulation which serve to add specificity to the roles of individual peptides. These include post-translational modification, tissue-specific expression, regulation of receptor expression, the subcellular localization of the receptor and the potential for longdistance movement. Recent bioinformatic approaches have indicated that over 7,000 small, unannotated open reading frames exist in the A. thaliana genome (Hanada et al., 2013). As proportion of these are likely to be regulatory peptide-encoding genes, 
there is still a long way to go in fully exploring the extent of peptide-mediated developmental regulation.

\section{ACKNOWLEDGMENTS}

Christina Delay was supported by an Australia Postgraduate Award and GRDC Grains Industry Research Scholarship (GRS10329).

\section{REFERENCES}

Aida, M., Beis, D., Heidstra, R., Willemsen, V., Blilou, I., Galinha, C., et al. (2004). The PLETHORA genes mediate patterning of the Arabidopsis root stem cell niche. Cell 119, 109-120. doi: 10.1016/j.cell.2004.09.018

Brand, U., Fletcher, J. C., Hobe, M., Meyerowitz, E. M., and Simon, R. (2000). Dependence of stem cell fate in Arabidopsis on a feedback loop regulated by CLV3 activity. Science $289,617-619$. doi: $10.1126 /$ science.289.5479.617

Butenko, M. A., Patterson, S. E., Grini, P. E., Stenvik, G.-E., Amundsen, S. S., Mandal, A., et al. (2003). INFLORESCENCE DEFICIENT IN ABSCISSION controls floral organ abscission in Arabidopsis and identifies a novel family of putative ligands in plants. Plant Cell 15, 2296-2307. doi: 10.1105/tpc.014365

Caetano-Anolles, G., and Gresshoff, P. M. (1991). Plant genetic control of nodulation. Annu. Rev. Microbiol. 45, 345-382. doi: 10.1146/annurev. mi.45.100191.002021

Casimiro, I., Beeckman, T., Graham, N., Bhalerao, R., Zhang, H., Casero, P., etal. (2003). Dissecting Arabidopsis lateral root development. Trends Plant Sci. 8, 165-171. doi: 10.1016/S1360-1385(03)00051-7

Cock, J. M., and McCormick, S. (2001). A large family of genes that share homology with CLAVATA3. Plant Physiol. 126, 939-942. doi: 10.1104/pp.126.3.939

De Smet, I., Tetsumura, T., De Rybel, B. Frey, N. F. D., Laplaze, L., Casimiro, I., et al. (2007). Auxin-dependent regulation of lateral root positioning in the basal meristem of Arabidopsis. Development 134, 681-690. doi $10.1242 / \mathrm{dev} .02753$

Di Laurenzio, L., Wysocka-Diller, J., Malamy, J. E., Pysh, L., Helariutta, Y., Freshour, G., et al. (1996). The SCARECROW gene regulates an asymmetric cell division that is essential for generating the radial organization of the Arabidopsis root. Cell 86, 423-433. doi: 10.1016/S00928674(00)80115-4

Dubrovsky, J. G., Napsucialy-Mendivil, S., Duclercq, J., Cheng, Y., Shishkova, S., Ivanchenko, M. G., et al. (2011). Auxin minimum defines a developmental window for lateral root initiation. New Phytol. 191, 970-983. doi: 10.1111/j.14698137.2011.03757.x

Dubrovsky, J. G., Sauer, M., NapsucialyMendivil, S., Ivanchenko, M. G. Friml, J., Shishkova, S., et al. (2008). Auxin acts as a local morphogenetic trigger to specify lateral root founder cells. Proc. Natl. Acad. Sci. U.S.A. 105, 8790-8794. doi: 10.1073/pnas.0712307105

Fernandez, A., Drozdzecki, A. Hoogewijs, K., Nguyen, A., Beeckman, T., Madder, A., et al. (2013). Transcriptional and functional classification of the GLV/RGF/CLEL signaling peptides reveals their role in lateral root and hair formation. Plant Physiol. 161, 954-970. doi: 10.1104/pp.112.206029

Friml, J., Vieten, A., Sauer, M., Weijers, D., Schwarz, H., Hamann, T., et al. (2003). Efflux-dependent auxin gradients establish the apical-basal axis of Arabidopsis. Nature 426, 147-153. doi: 10.1038/nature02085

Fukuda, H., and Higashiyama, T. (2011). Diverse functions of plant peptides: entering a new phase. Plant Cell Physiol. 52, 1-4. doi: $10.1093 /$ pcp/pcq193 M., Willemsen, V., Blilou, I., Heidstra, R., et al. (2007). PLETHORA proteins as dose-dependent master regulators of Arabidopsis root development. Nature 449, 1053-1057. doi: 10.1038/nature06206

Haecker, A., Groß-Hardt, R., Geiges, B., Sarkar, A., Breuninger, H., Herrmann, M., et al. (2004). Expression dynamics of WOX genes mark cell fate decisions during early embryonic patterning in Arabidopsis thaliana. Development 131, 657-668. doi: $10.1242 / \mathrm{dev} .00963$

Hanada, K., Higuchi-Takeuchi, M., Okamoto, M., Yoshizumi, T., Shimizu, M., Nakaminami, K. et al. (2013). Small open reading frames associated with morphogenesis are hidden in plant genomes. Proc. Natl. Acad. Sci. U.S.A. 110 2395-2400. doi: 10.1073/pnas.1213 958110

Helariutta, Y., Fukaki, H., WysockaDiller, J., Nakajima, K., Jung, J., Sena, gene controls radial patterning of the Arabidopsis root through radial
Galinha, C., Hofhuis, H., Luijten, G., et al. (2000). The SHORT-ROOT

This work was supported by an Australian Research Council grant to Michael A. Djordjeric and Nijat Imin (DP140103714).

\section{CONTRIBUTION}

Christina Delay wrote the paper. Nijat Imin and Michael A. Djordjevic critically read and edited the paper.

signaling. Cell 101, 555-567. doi: 10.1016/S0092-8674(00)80865-X

Hirakawa, Y., Shinohara, H., Kondo, Y. Inoue, A., Nakanomyo, I., Ogawa, M. et al. (2008). Non-cell-autonomous control of vascular stem cell fate by a CLE peptide/receptor system. Proc. Natl. Acad. Sci. U.S.A. 105, 15208 15213. doi: 10.1073/pnas. 08084 44105

Ito, Y., Nakanomyo, I., Motose, H., Iwamoto, K., Sawa, S., Dohmae, N. et al. (2006). Dodeca-CLE peptides as suppressors of plant stem cell differentiation. Science 313, 842-845. doi: 10.1126/science. 1128436

Jun, J., Fiume, E., Roeder, A. H. K., Meng, L., Sharma, V. K., Osmont K. S., etal. (2010). Comprehensive analysis of CLE polypeptide signaling gene expression and overexpression activity in Arabidopsis. Plant Physiol. 154, 1721-1736. doi: 10.1104/pp.110.163683

Kondo, Y., Hirakawa, Y., Kieber, J. J., and Fukuda, H. (2011). CLE peptides can negatively regulate protoxylem vessel formation via cytokinin signaling. Plant Cell Physiol. 52, 37-48. doi: $10.1093 / \mathrm{pcp} / \mathrm{pcq} 129$

Kumpf, R. P., Shi, C.-L., Larrieu, A., Stø, I. M., Butenko, M. A., Péret, B., et al. (2013). Floral organ abscission peptide IDA and its HAE/HSL2 receptors control cell separation during lateral root emergence. Proc Natl. Acad. Sci. U.S.A. 110, 5235-5240. doi: 10.1073/pnas. 12108 35110

Leibfried, A., To, J. P. C., Busch, W., Stehling, S., Kehle, A., Demar, M., etal. (2005). WUSCHEL controls meristem function by direct regulation of cytokinin-inducible response regulators. Nature 438, 1172-1175. doi: 10.1038/nature04270

Malamy, J. E. (2005). Intrinsic and environmental response pathways that regulate root system architecture. Plant Cell Environ. 28, 67-77. doi: 10.1111/j.1365-3040.2005.01306.x

Malamy, J. E., and Benfey, P. N. (1997). Organization and cell differentiation in lateral roots of Arabidopsis thaliana. Development 124, 33-44.

Matsubayashi, Y., Ogawa, M., Morita, A., and Sakagami, Y. (2002). An LRR receptor kinase involved in perception of a peptide plant hormone, phytosulfokine. Science 296
1470-1472. doi: 10.1126/science. 1069607

Matsuzaki, Y., Ogawa-Ohnishi, M., Mori, A., and Matsubayashi, Y. (2010). Secreted peptide signals required for maintenance of root stem cell niche in Arabidopsis. Science 329, 1065-1067. doi: 10.1126/science.1191132

Mayer, K. F. X., Schoof, H., Haecker, A., Lenhard, M., Jürgens, G., and Laux, T. (1998). Role of WUSCHEL in regulating stem cell fate in the Arabidopsis shoot meristem. Cell 95, 805815. doi: $10.1016 / \mathrm{S} 0092-8674(00)$ 81703-

Meng, L., Buchanan, B. B., Feldman, L. J., and Luan, S. (2012a). CLE-like (CLEL) peptides control the pattern of root growth and lateral root development in Arabidopsis. Proc. Natl. Acad. Sci. U.S.A. 109, 1760-1765. doi: 10.1073/pnas.1119864109

Meng, L., Buchanan, B. B., Feldman, L. J., and Luan, S. (2012b). A putative nuclear CLE-Like (CLEL) peptide precursor regulates root growth in Arabidopsis. Mol. Plant 5, 955-957. doi: $10.1093 / \mathrm{mp} / \mathrm{sss} 060$

Moreno-Risueno, M. A., Van Norman, J. M., Moreno, A., Zhang, J., Ahnert, S. E., and Benfey, P. N. (2010). Oscillating gene expression determines competence for periodic Arabidopsis root branching. Science 329, 1306-1311. doi: 10.1126/science.11 91937

Mortier, V., Den Herder, G., Whitford, R., Van De Velde, W., Rombauts, S., D'haeseleer, K., et al. (2010). CLE peptides control Medicago truncatula nodulation locally and systemically. Plant Physiol. 153, 222-237. doi: 10.1104/pp.110.153718

Ni, J., Guo, Y., Jin, H., Hartsell, J., and Clark, S. (2011). Characterization of a CLE processing activity. Plant Mol. Biol. 75, 67-75. doi: 10.1007/s11103010-9708-2

Ogawa, M., Shinohara, H., Sakagami, Y., and Matsubayashi, Y. (2008). Arabidopsis CLV3 peptide directly binds CLV1 ectodomain. Science 319, 294. doi: 10.1126/science.1150083

Ohyama, K., Ogawa, M., and Matsubayashi, Y. (2008). Identification of a biologically active, small, secreted peptide in Arabidopsis by in silico gene screening, followed by LC-MSbased structure analysis. Plant 
55, 152-160. doi: 10.1111/j.1365313X.2008.03464.x

Okamoto, S., Ohnishi, E., Sato, S., Takahashi, H., Nakazono, M., Tabata, S., et al. (2009). Nod factor/nitrateinduced CLE genes that drive HAR1mediated systemic regulation of nodulation. Plant Cell Physiol. 50, 67-77. doi: 10.1093/pcp/pcn 194

Okamoto, S., Shinohara, H., Mori, T., Matsubayashi, Y., and Kawaguchi, M. (2013). Root-derived CLE glycopeptides control nodulation by direct binding to HARl receptor kinase. Nat. Commun. 4, article number 2191. doi: 10.1038/ncomms3191

Osipova, M. A., Mortier, V., Demchenko, K. N., Tsyganov, V. E., Tikhonovich, I. A., Lutova, L. A. et al. (2012). WUSCHEL-RELATED HOMEOBOX5 gene expression and interaction of CLE peptides with components of the systemic control add two pieces to the puzzle of autoregulation of nodulation. Plant Physiol. 158, 1329-1341. doi: 10.1104/pp.111.188078

Reid, D. E., Ferguson, B. J., and Gresshoff, P. M. (2011). Inoculationand nitrate-induced CLE peptides of Soybean control NARK-dependent nodule formation. Mol. Plant Microbe Interact. 24, 606-618. doi: 10.1094/MPMI-09-10-0207

Sabatini, S., Beis, D., Wolkenfelt, H., Murfett, J., Guilfoyle, T., Malamy, J., et al. (1999). An auxindependent distal organizer of pattern and polarity in the Arabidopsis root.
Cell 99, 463-472. doi: 10.1016/S00928674(00)81535-4

Sabatini, S., Heidstra, R., Wildwater, M., and Scheres, B. (2003). SCARECROW is involved in positioning the stem cell niche in the Arabidopsis root meristem. Genes Dev. 17, 354-358. doi: 10.1101/gad.252503

Saur, I. M. L., Oakes, M., Djordjevic, M. A., and Imin, N. (2011). Crosstalk between the nodulation signaling pathway and the autoregulation of nodulation in Medicago truncatula. New Phytol. 190, 865-874. doi: 10.1111/j.1469-8137.2011.03738.x

Schoof, H., Lenhard, M., Haecker, A., Mayer, K. F. X., Jürgens, G., and Laux, T. (2000). The stem cell population of Arabidopsis shoot meristems is maintained by a regulatory loop between the CLAVATA and WUSCHEL genes. Cell 100, 635644. doi: 10.1016/S0092-8674(00) 80700-X

Song, X.-F., Guo, P., Ren, S.-C. $\mathrm{Xu}, \mathrm{T} .-\mathrm{T}$, , and Liu, C.-M. (2013). Antagonistic peptide technology for functional dissection of CLV3/ESR genes in Arabidopsis. Plant Physiol. 161, 1076-1085. doi: 10.1104/pp.112. 211029

Stahl, Y., Grabowski, S., Bleckmann, A., Kühnemuth, R., WeidtkampPeters, S., Pinto, K. G., et al. (2013). Moderation of Arabidopsis root stemness by CLAVATA1 and ARABIDOPSIS CRINKLY4 receptor kinase complexes. Curr. Biol. 23, 362371. doi: 10.1016/j.cub.2013.01.045
Stahl, Y., Wink, R. H., Ingram, G. C., and Simon, R. (2009). A signaling module controlling the stem cell niche in Arabidopsis root meristems. Curr. Biol. 19, 909-914. doi: 10.1016/j.cub.2009.03.060

Stenvik, G.-E., Tandstad, N. M., Guo, Y., Shi, C.-L., Kristiansen, W. Holmgren, A., etal. (2008). The EPIP peptide of INFLORESCENCE DEFICIENT IN ABSCISSION is sufficient to induce abscission in Arabidopsis through the receptorlike kinases HAESA and HAESALIKE2. Plant Cell 20, 1805-1817. doi 10.1105/tpc.108.059139

Swarup, K., Benkova, E., Swarup, R. Casimiro, I., Peret, B., Yang, Y., et al. (2008). The auxin influx carrier LAX3 promotes lateral root emergence. Nat. Cell Biol. 10, 946-954. doi: 10.1038/ncb1754

Vieten, A., Sauer, M., Brewer, P. B., and Friml, J. (2007) Molecular and cellular aspects of auxin-transport-mediated development. Trends Plant Sci. 12, 160-168. doi: 10.1016/j.tplants.2007.03.006

Whitford, R., Fernandez, A., Tejos, R., Pérez, A. C., Kleine-Vehn, J., Vanneste, S., et al. (2012). GOLVEN secretory peptides regulate auxin carrier turnover during plant gravitropic responses. Dev. Cell 22, 678-685. doi: 10.1016/j.devcel.2012. 02.002

Zhou, W., Wei, L., Xu, J., Zhai, Q., Jiang, H., Chen, R., et al. (2010). Arabidopsis tyrosylprotein sulfotransferase acts in the auxin/PLETHORA pathway in regulating postembryonic maintenance of the root stem cell niche. Plant Cell 22, 3692-3709. doi: 10.1105/tpc.110. 075721

Conflict of Interest Statement: The authors declare that the research was conducted in the absence of any commercial or financial relationships that could be construed as a potential conflict of interest.

Received: 04 July 2013; accepted: 21 August 2013; published online: 06 September 2013

Citation: Delay C, Imin N and Djordjevic MA (2013) Regulation of Arabidopsis root development by small signaling peptides. Front. Plant Sci. 4:352. doi: 10.3389/fpls.2013.00352

This article was submitted to Plant Systems Biology, a section of the journal Frontiers in Plant Science.

Copyright $(2013$ Delay, Imin and Djordjevic. This is an open-access article distributed under the terms of the Creative Commons Attribution License (CC BY). The use, distribution or reproduction in other forums is permitted, provided the original author(s) or licensor are credited and that the original publication in this journal is cited, in accordance with accepted academic practice. No use, distribution or reproduction is permitted which does not comply with these terms. 